\title{
17. MAGNETIC VISCOSITY AND PALEOMAGNETISM OF THE BASEMENT COMPLEX AT CATOCHE KNOLL DEEP SEA DRILLING PROJECT HOLE 538A, LEG 77, SOUTHEASTERN GULF OF MEXICO ${ }^{1}$
}

\author{
Margaret M. Testarmata, Institute for Geophysics, University of Texas at Austin, Austin, Texas \\ and \\ Wulf A. Gose, Department of Geological Sciences and Institute for Geophysics, \\ University of Texas at Austin, Austin, Texas
}

\begin{abstract}
The basement at Catoche Knoll consists of Paleozoic gneiss and amphibolite intruded by several generations of early Jurassic diabase dikes. Upon exposure to a 1-oersted field for 9 days, the diabase and amphibolite acquire a viscous remanent magnetization (VRM) which ranges from 42 to $2047 \%$ of their natural remanent magnetization (NRM). A magnetic field of similar intensity is observed in the paleomagnetic facility of the Glomar Challenger, and it is therefore doubtful if accurate measurements of magnetic moments in such rocks can be made on board unless the facility is magnetically shielded. The significant VRM also indicates the futility of attempting to discern magnetic lineations from an ocean floor composed of such rocks. No strong correlation exists between the Königsberger ratio, which is usually less than 1, and the tendency to acquire a VRM. The VRM decay is typical of a Richter aftereffect, but the relaxation times vary widely among the samples studied. A stable remanence is observed after alternating field demagnetization to $200 \mathrm{Oe}$. The range of magnetic inclinations in the diabase dikes is consistent with ${ }^{40} \mathrm{Ar} /{ }^{39} \mathrm{Ar}$ dates of 190 and $160 \mathrm{Ma}$. The inclinations suggest that the Catoche Knoll block tilted more than $20^{\circ}$ to the north after the final dike intrusion.
\end{abstract}

\section{INTRODUCTION}

The basement complex at Catoche Knoll consists of a metamorphic terrane of interlayered gneiss and amphibolite intruded by several generations of undeformed diabase dikes. ${ }^{40} \mathrm{Ar} /{ }^{39} \mathrm{Ar}$ dates (Dallmeyer, this volume) show that the metamorphic rocks are approximately $500 \mathrm{Ma}$ old and have a mild late Paleozoic thermal overprint. Dates from the dikes range from 190 to $160 \mathrm{Ma}$, Early Jurassic, which is the inferred time for spreading in the Gulf of Mexico. The basement at Hole 538A, therefore, seems to represent the initial stages of a rifting event which was later aborted. Paleomagnetic studies of the basement rocks were designed to examine their magnetic properties and to contribute to a better understanding of their history.

\section{NATURAL REMANENT MAGNETIZATION AND SUSCEPTIBILITY}

From the $64 \mathrm{~m}$ of basement penetrated, approximately $28 \mathrm{~m}$ were recovered in the following proportions: gneiss, $15 \%$; amphibolite, $30 \%$; and diabase, $55 \%$. All three rock types are locally affected by low-temperature hydrothermal or deuteric alteration. Paleomagnetic sampling was concentrated in the unaltered intervals, with 21 vertically oriented minicores from the diabase and 5 from the amphibolite. Measurements of NRM and initial susceptibility $(\kappa)$ were made on board the Glomar Challenger. NRM measurements were made with a Digico magnetometer located in the hull of the ship. Long term monitoring of the magnetic field in this area indi-

\footnotetext{
${ }^{1}$ Buffler, R. T., Schlager, W., et al., Init. Repts. DSDP, 77: Washington (U.S. Govt. Printing Office).
}

cated that a horizontal field of approximately 0.9 Oe was parallel to the length of the ship and that its strength and direction varied approximately $10 \%$ with the orientation of the ship. Because a field of such strength and consistency has the potential to impart a significant viscous magnetization, the NRM may have been influenced by the ambient field. Susceptibility measurements were made with the shipboard Bison Model 3101 Susceptibility Bridge.

All samples were studied postcruise in the paleomagnetic laboratory of the University of Texas (U.T.) where they were stored in a magnetically shielded room $(\sim 100 \gamma)$ for several months prior to remeasurement of their NRM. The intensities and inclinations are compared with the shipboard measurements in Table 1 . The intensity differences may be partially due to the different calibrations of the shipboard Digico and the U.T. cryogenic magnetometer. However, changes in inclination and both increases and decreases in intensity suggest that viscous components of magnetization have been acquired or have decayed between the two sets of measurements. The Königsberger ratio $(Q)$, which is the ratio of remanent to induced magnetization, is extremely low; $50 \%$ of the samples have values of less than 0.5 , and only $19 \%$ have $Q$ s greater than 1 . These values are much lower than those observed in Leg 76 basalts, which Testarmata and Gose (1983) demonstrated could acquire a significant component of viscous magnetization. There is, however, only a weak inverse correlation between the amount of change in NRM intensity and inclination over time and the $Q$ value (Fig. 1). The correlation appears stronger for the Leg 76 basalts than for the Hole 538A basement rocks, probably because of the wider range in $Q$ values for the basalts. 
Table 1. Comparison of shipboard and land-based measurements of NRM intensity and inclination and initial susceptibility $(\kappa)$ and Königsberger ratio $(Q)$, Hole 538A.

\begin{tabular}{|c|c|c|c|c|c|c|c|c|c|c|}
\hline \multirow{2}{*}{$\begin{array}{c}\text { Sample } \\
\text { (core-section, } \mathrm{cm} \\
\text { from top of section) }\end{array}$} & \multirow{2}{*}{$\begin{array}{l}\text { Rock } \\
\text { type }\end{array}$} & \multirow{2}{*}{$\begin{array}{l}\text { Sub-bottom } \\
\text { depth } \\
\text { (m) }\end{array}$} & \multicolumn{3}{|c|}{$\begin{array}{c}\text { NRM intensity } \\
\left(\times 10^{-4} \mathrm{emu} / \mathrm{cm}^{3}\right)\end{array}$} & \multicolumn{3}{|c|}{ NRM inclination $\left({ }^{\circ}\right)$} & \multirow[b]{2}{*}{$x^{\mathrm{a}}$} & \multirow[b]{2}{*}{$Q^{\mathrm{b}}$} \\
\hline & & & $G C$ & U.T. & $\Delta(\%)$ & $G C$ & U.T. & $\Delta$ & & \\
\hline $31-1,12$ & $\mathrm{D}_{\mathrm{f}}^{\mathrm{f}}$ & 278.12 & 3.78 & 3.06 & -19 & 19.9 & 18.8 & -1.1 & 15.9 & 0.41 \\
\hline $31-1,23$ & $D^{f *}$ & 278.23 & 2.84 & 2.31 & -19 & 40.8 & 21.1 & -19.7 & 21.1 & 0.23 \\
\hline $32-1,21$ & D & 287.71 & 6.79 & 7.33 & +8 & 10.0 & 3.3 & -6.7 & 33.6 & 0.47 \\
\hline $32-1,85$ & D & 288.35 & 6.65 & 7.70 & +16 & -7.3 & -7.0 & +0.3 & 28.1 & 0.59 \\
\hline $32-1,132$ & D & 288.82 & 8.23 & 9.67 & +17 & 3.2 & 2.2 & -5.4 & 32.5 & 0.64 \\
\hline $32-2,30$ & D & 289.30 & 5.32 & 6.72 & +26 & 11.7 & 11.2 & -0.5 & 33.2 & 0.43 \\
\hline $32-2,106$ & D & 290.06 & 6.74 & 8.42 & +25 & -6.8 & -18.3 & -11.5 & 31.1 & 0.58 \\
\hline $32-3,70$ & D & 291.20 & 5.34 & 5.83 & +9 & 27.8 & 5.4 & -22.4 & 32.4 & 0.38 \\
\hline $32-4,16$ & D & 292.16 & 9.05 & 9.33 & +3 & 32.0 & 28.5 & -3.5 & 32.6 & 0.61 \\
\hline $32-5,33$ & D & 293.83 & 5.73 & 7.07 & +23 & -3.3 & -10.9 & -7.6 & 29.7 & 0.51 \\
\hline $32-5,141$ & D & 294.91 & 5.85 & 6.30 & +8 & 23.8 & 17.9 & -5.9 & 20.5 & 0.66 \\
\hline $32-6,77$ & D & 295.77 & 5.70 & 7.03 & +23 & 6.5 & 5.5 & -1.0 & 35.0 & 0.43 \\
\hline $32-7,25$ & D & 296.75 & 7.67 & 8.50 & +11 & 8.2 & 3.3 & -4.9 & 35.3 & 0.51 \\
\hline $33-2,81$ & A & 298.81 & 0.026 & 0.014 & -46 & 22.5 & 4.2 & -18.3 & 0.67 & 0.04 \\
\hline $33-3,52$ & A & 300.02 & 0.111 & 0.137 & +23 & 44.0 & 25.9 & -18.1 & 1.32 & 0.22 \\
\hline $34-1,31$ & A & 305.81 & 0.092 & 0.097 & +5 & 63.1 & 56.3 & -6.8 & 0.91 & 0.23 \\
\hline $34-1,40$ & A & 305.90 & 0.117 & 0.111 & -5 & 54.7 & 47.9 & -6.8 & 1.06 & 0.22 \\
\hline $34-1,70$ & A & 306.20 & 0.161 & 0.169 & +5 & 34.9 & 35.3 & +0.4 & 1.20 & 0.30 \\
\hline $35-1,14$ & $\mathrm{D}^{*}$ & 314.64 & 4.39 & 3.88 & -12 & 22.8 & 18.8 & -4.0 & 11.4 & 0.73 \\
\hline $35-3,146$ & D & 318.96 & 15.33 & 17.3 & +13 & 55.6 & 53.6 & -2.0 & 31.5 & 1.17 \\
\hline $35-4,18$ & D & 319.18 & 18.70 & 19.5 & +4 & 43.5 & 45.3 & +1.8 & 37.0 & 1.13 \\
\hline $35-4,94$ & D & 319.94 & 28.25 & 31.0 & +10 & 50.1 & 46.1 & -4.0 & 37.3 & 1.78 \\
\hline $36-1,57$ & D & 324.07 & 21.90 & 23.8 & +9 & 26.7 & 24.8 & -1.9 & 43.5 & 1.17 \\
\hline $36-1,89$ & D & 324.39 & 16.81 & 22.2 & +32 & 17.8 & 8.7 & -9.1 & 41.1 & 1.15 \\
\hline $36-2,86$ & D & 325.86 & 6.23 & 6.68 & +10 & 25.6 & -1.2 & -26.8 & 38.4 & 0.38 \\
\hline $36-3,21$ & D & 326.71 & 2.06 & 2.21 & -7 & 40.7 & 46.1 & +5.4 & 11.5 & 0.41 \\
\hline
\end{tabular}

Note: $\mathrm{D}=$ diabase; $\mathrm{A}=$ Amphibolite; ${ }^{*}=$ moderately altered; $G C=$ measured on Digico magnetometer aboard Glomar Challenger. U.T. = measured on cryogenic magnetometer at University of Texas, Austin.

a Initial susceptibility, $\times 10^{-4} \mathrm{G} / \mathrm{Oe}$.

${ }^{b}$ Königsberger ratio, calculated using U.T. NRM intensities; $\mathrm{H}=0.468 \mathrm{Oe}$
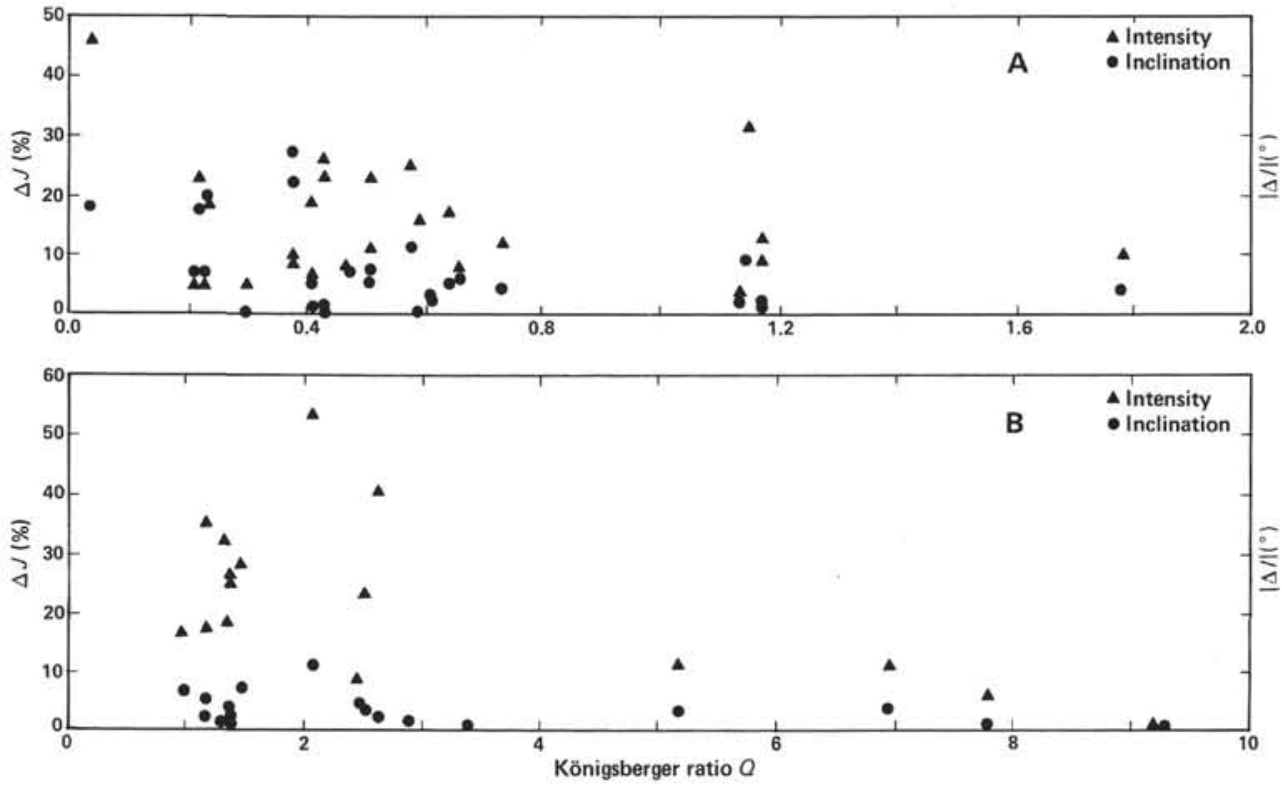

Figure 1. Change in NRM intensity $(\Delta J)$ and inclination $(\Delta I)$ as a function of Königsberger ratio $Q$ for (A) Hole 538A diabase and amphibolite and (B) Hole 534A oceanic basalts. Changes are between measurements made aboard the Glomar Challenger and land-based measurements made several months later, after the samples had been stored in a low magnetic field environment. Triangles indicate intensity data; closed circles indicate inclination data.

\section{TIME-DEPENDENT MAGNETIZATION}

\section{Experimental Results}

The propensity for acquiring a viscous component of magnetization was studied for seven diabase samples and one amphibolite. After NRMs were remeasured, the samples were placed in a 1-Oe field, produced by a coil lo- cated inside a large $\mu$-metal cylinder. In all cases, the field was applied along the axis of the cylindrical specimen. After the samples were exposed to the 1-Oe field for 9 days, decay of the acquired magnetization was measured in a field-free environment with a cryogenic magnetometer interfaced with a computer. Measurements of the axial component were recorded continuously, begin- 
ning about $15 \mathrm{~s}$ after removal from the field and continuing for approximately 100 minutes. The sample then remained in a zero magnetic field $(\sim 5 \gamma)$, and two additional decay measurements were taken at about 1,000 and 10,000 minutes for all but one sample (538A-35-4, $18 \mathrm{~cm}$ ). Table 2 details the experimental sequence and presents the results as relative intensities with respect to the NRMs measured in the laboratory.

The decay of the acquired VRM is shown in Figure 2. All samples behave in a similar manner, including the single amphibolite, Sample 538A-34-1, $31 \mathrm{~cm}$. In no case is the initial 100 minutes of decay linear with the logarithm of time. Sample 538A-35-4, $18 \mathrm{~cm}$ exhibits a decay typical of the Richter aftereffect (Chikazumi, 1964). The rate of decay is low initially, and gradually increases with time; then after passing through an inflection point, it starts decreasing and eventually becomes zero. This effect is observed whenever there exists a population of magnetic grains with relaxation times no greater than the duration of the experiment. The Richter aftereffect is usually associated with single domain grains (e.g., Gose and Carnes, 1973) and was observed in the basalt samples from DSDP Leg 76 (Testarmata and Gose, 1983).

The other samples show lesser portions of the Richter-type curve during their first 100 minutes of decay. In Figure 2 the samples are arranged from bottom to top in order of decreasing Richter-type behavior. The lower curves show an inflection point and a roll-off in the decay rate. The upper curves never reach this inflection point and exhibit only an increase in the rate of decay during the first 100 minutes. Their shape supports Dunlop's (1983) contention that the initial decay of VRM obeys a $(\log t)^{2}$ law rather than the generally assumed $\log t$ dependence.

Only two instantaneous measurements were made after the initial 100 minutes of decay, so the curves (Fig. 2) have been extrapolated into this region. Sample 538A-35-1,
$14 \mathrm{~cm}$ continues the same trend that it displayed in the first 100 minutes. The other samples that had not displayed an inflection point in the first 100 minutes seem to have passed through it and are in the roll-off stage of the Richter behavior by 10,000 minutes. Four samples (538A-35-2, $106 \mathrm{~cm}$; 538A-34-1, $31 \mathrm{~cm}$; 538A-36-1, 89 $\mathrm{cm}$; 538A-32-7, $25 \mathrm{~cm}$ ), which had shown signs of rolloff within the first 100 minutes, apparently did not continue this simple behavior for longer periods. The measurements at 1000 minutes imply that their decay rates increased a second time. By 10,000 minutes they seem to have reentered the roll-off stage. Continuous monitoring in this time range is needed to resolve this behavior, but it seems to be the sum of two Richter-type curves, implying two distinct grain populations.

\section{Discussion}

The results of this experiment show that these basement rocks, when exposed to a 1-Oe field for 9 days, can acquire a viscous magnetization which is a significant percentage of the NRM ranging from 42 to $2047 \%$. Exposure to the Earth's 0.5-Oe field for several thousand years would result in a VRM that completely masks the original thermoremanent magnetization (TRM) of the rocks. Attempting to discern magnetic lineations in an ocean floor composed of such rocks would therefore be futile. The presence of a significant VRM also emphasizes the need for a field-free space on the Glomar Challenger where samples can be stored and measured without being affected by the ambient field.

As the low Königsberger ratio suggested, these samples can readily acquire a VRM. However, as observed earlier for Leg 76 basalts (Testarmata and Gose, 1983), there is no simple correlation between $Q$ and viscosity (Fig. 3). It should be noted, though, that the samples from Hole 538A had a lower average $Q$ than the Hole 534A basalts and that they also acquired a larger VRM on the average.

Table 2. Relative intensity of axial component of magnetization for the 9 samples from Hole 538A subjected to the viscosity experiment described in the text.

\begin{tabular}{|c|c|c|c|c|c|c|c|c|c|c|c|}
\hline $\begin{array}{c}\text { Sample } \\
\text { (core-section, cm } \\
\text { from top of section) }\end{array}$ & $\begin{array}{c}\text { NRM } \\
G C\end{array}$ & $\underset{\text { (month) }}{\Delta \tau_{0}}$ & $\begin{array}{l}\text { NRM } \\
\text { U.T. }\end{array}$ & $\begin{array}{c}\Delta \tau_{1} \\
\text { (day) }\end{array}$ & VRM & $\underset{\text { (min.) }}{\Delta \tau_{2}}$ & Decay 1 & $\begin{array}{l}\Delta \tau_{3} \\
\text { (hr.) }\end{array}$ & Decay 2 & $\begin{array}{c}\Delta \tau_{4} \\
\text { (day) }\end{array}$ & Decay 3 \\
\hline $31-1,12$ & 1.33 & 2.7 & $\begin{array}{l}2.46 \\
1.00 \\
\end{array}$ & 9.2 & -0.44 & 69 & 0.01 & 11.7 & 0.41 & 6.5 & 0.58 \\
\hline $31-1,23$ & 1.00 & 2.7 & $\begin{array}{r}-2.15 \\
1.00 \\
\end{array}$ & 9.1 & 2.38 & 88 & 1.09 & 13.1 & 1.49 & 6.5 & 1.27 \\
\hline $32-2,106$ & 1.00 & 2.7 & $\begin{array}{r}-4.20 \\
1.00 \\
\end{array}$ & 9.0 & 1.75 & 96 & 1.50 & 14.5 & 1.34 & 6.5 & 1.22 \\
\hline $32-7,25$ & 0.88 & 2.7 & $\begin{array}{l}8.32 \\
1.00 \\
\end{array}$ & 9.0 & 0.47 & 86 & 0.66 & 16.2 & 0.80 & 6.5 & 0.87 \\
\hline $34-1,31$ & 0.84 & 2.7 & $\begin{array}{l}0.041 \\
1.00 \\
\end{array}$ & 8.9 & 0.42 & 61 & 0.68 & 19.0 & 0.79 & 6.5 & 0.86 \\
\hline $35-1,14$ & 1.20 & 2.7 & $\begin{array}{r}-3.00 \\
1.00\end{array}$ & 8.8 & 1.43 & 111 & 1.29 & 20.0 & 1.21 & 6.5 & 1.15 \\
\hline $35-4,18$ & & 2.7 & $\begin{array}{l}2.98 \\
1.00\end{array}$ & 3.9 & 0.13 & 50 & 0.51 & - & - & - & - \\
\hline $36-1,89$ & 0.79 & 2.7 & $\begin{array}{l}5.57 \\
1.00 \\
\end{array}$ & 8.9 & 1.56 & 78 & 1.33 & 17.7 & 1.20 & 6.5 & 1.13 \\
\hline $36-3,21$ & 3.94 & 2.7 & $\begin{array}{c}-0.121 \\
1.00\end{array}$ & 8.7 & 21.47 & 123 & 16.40 & 22.0 & 9.3 & 6.5 & 6.1 \\
\hline
\end{tabular}

Note: For each sample, the top line lists the time between measurements $(\Delta \tau)$ and the NRM intensity of the axial component $\left(\times 10^{-4} \mathrm{emu} / \mathrm{cm}^{3}\right)$ before the sample was placed in a 1-Oe field for a time $\Delta \tau_{1}$. The bottom line lists all measurements relative to this intensity. $G C=$ Glomar Challenger measurements. U.T. = measurements taken at University of Texas, Austin. 


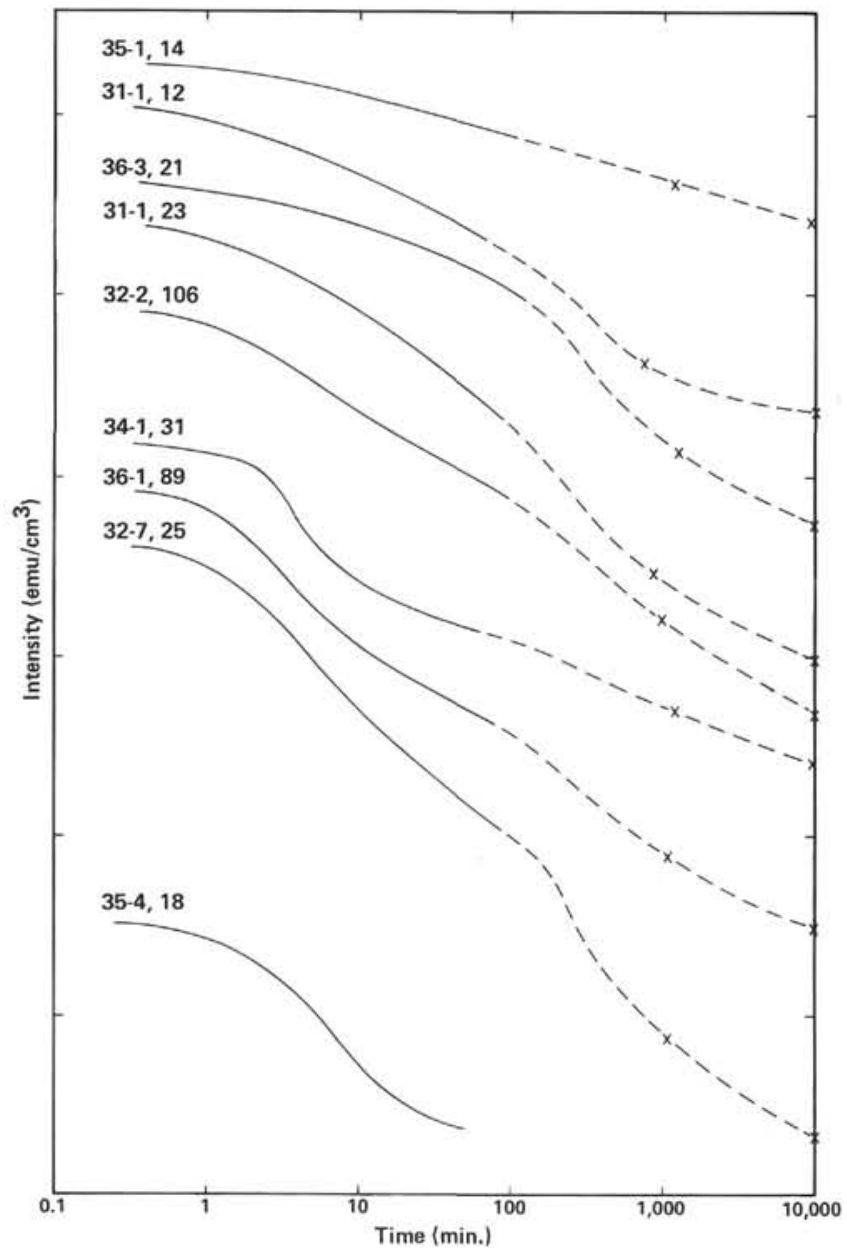

Figure 2. Change in intensity of axial component of 9 samples from Hole 538A upon removal from a 1-Oe field after 9 days of exposure. Vertical intervals in plot are $1 \times 10^{-4} \mathrm{emu} / \mathrm{cm}^{3}$ for all samples except 538A-34-1, 31 in which case intervals are $1 \times 10^{-6}$ $\mathrm{emu} / \mathrm{cm}^{3}$. The solid line represents the time of continuous recording. Sample numbers designate core-section, $\mathrm{cm}$ from top of section.

\section{STABLE MAGNETIZATION}

\section{Components of Magnetization}

The magnetic mineralogy of these rocks has been studied by Furuta and Kinoshita (this volume). They observed low-titanium magnetite, the product of high temperature oxidation during the intrusions. For this reason, alternating field (AF) demagnetization was used to isolate the stable inclination. An additional 9 samples collected postcruise were added to the study at this time. Their rock types, depths, and NRM values are listed in Table 3 . All 35 samples were demagnetized at 4 or $5 \mathrm{lev}$ els between 50 and $400 \mathrm{Oe}$, and further demagnetization at $100-\mathrm{Oe}$ intervals was performed on selected samples to a maximum of $700 \mathrm{Oe}$.

Figure 4 shows how the intensities of magnetization changed during the demagnetization process. The amphibolites have a distinctly lower intensity than the diabases, but most samples behaved in a similar manner upon demagnetization, as illustrated by orthogonal vec-

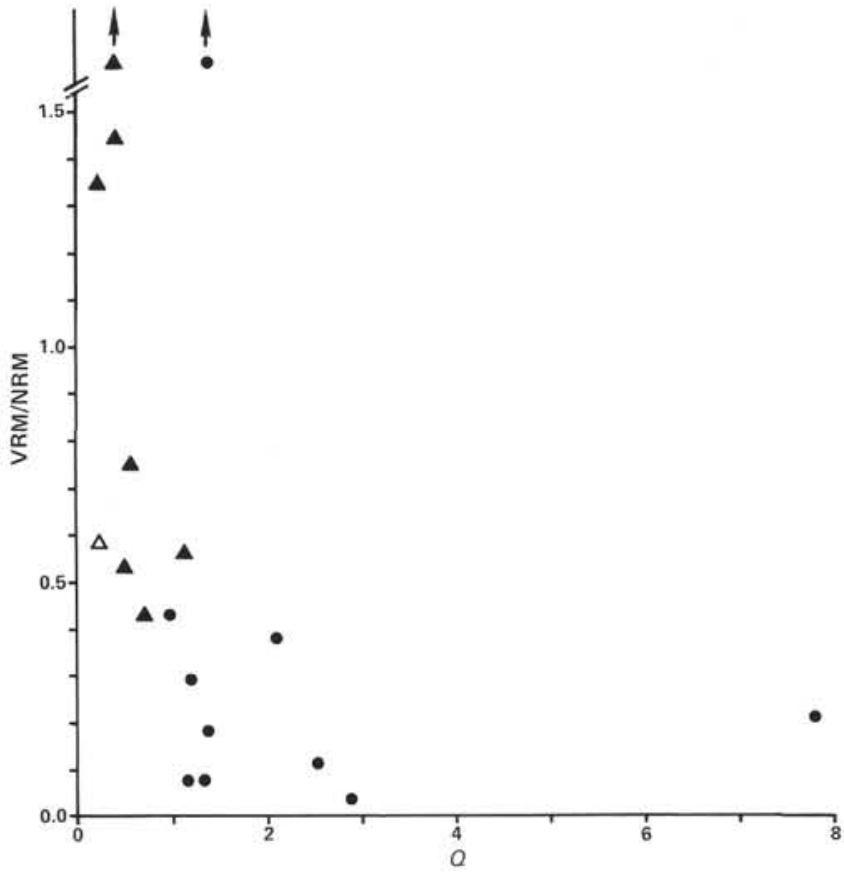

Figure 3. Normalized viscous remanent magnetization of $538 \mathrm{~A}$ diabases $(\Delta)$ and amphibolites $(\Delta)$, and 534A basalts ( $\bullet$ ) as a function of Königsberger ratio, $Q$. The diabase and basalt samples which plot off the graph have VRM/NRM values of 20.47 and 2.23 , respectively.

Table 3. NRM intensity and inclination for the 9 samples from Hole $538 \mathrm{~A}$ added to the study postcruise.

\begin{tabular}{ccccc}
\hline $\begin{array}{c}\text { Sample } \\
\text { (core-section, cm } \\
\text { from top of section) }\end{array}$ & $\begin{array}{c}\text { Rock } \\
\text { type }\end{array}$ & $\begin{array}{c}\text { Sub-bottom } \\
\text { depth } \\
(\mathrm{m})\end{array}$ & $\begin{array}{c}\text { NRM intensity } \\
\left(\times 10^{-4} \mathrm{emu} / \mathrm{cm}^{3}\right)\end{array}$ & $\begin{array}{c}\text { NRM inclination } \\
\left({ }^{\circ}\right)\end{array}$ \\
\hline $31-1,26$ & D* & 278.26 & 1.22 & 45.9 \\
$33-3,90$ & D & 291.40 & 10.1 & -21.1 \\
$32-5,68$ & D & 294.18 & 4.98 & -16.7 \\
$33-2,90$ & A & 298.90 & 0.012 & 5.1 \\
$34-1,94$ & A & 306.44 & 0.079 & 56.5 \\
$35-4,82$ & D & 319.82 & 28.9 & 37.9 \\
$36-2,92$ & D* & 325.92 & 5.13 & 6.8 \\
$36-3,27$ & D & 326.77 & 2.01 & 31.8 \\
$36-3,46$ & D* & 326.96 & 0.010 & 24.8 \\
\hline
\end{tabular}

Note: $\mathrm{D}=$ diabase; $\mathrm{A}=$ amphibolite; * = moderately altered.

tor diagrams (Fig. 5). Component 1 was usually removed by demagnetization to 100 or $200 \mathrm{Oe}$. Component 1 is in all but two cases of normal polarity (Table 4) and has a broad range of inclinations with a mean of $55^{\circ}$ (Fig. 6 ), within $1^{\circ}$ of the measured inclination a Hole 538A today $\left(56^{\circ}\right)$. These observations suggest that Component 1 is a VRM carried by grains with longer relaxation times than those activated in the viscosity experiment. Component 2, observed from $100-200$ Oe to 400 Oe or higher, is interpreted as the stable magnetization. It has a much tighter cluster around a mean absolute inclination of $20^{\circ}$ (Fig. 6). Four samples displayed an additional component of very high coercivity, usually evident above 500 Oe (e.g., Fig. 5D). In these 4 cases, because it was not clear which component represented the thermoremanence, a stable inclination was not interpreted.

One argument for the interpretation of Component 2 as the primary magnetization comes from comparing 

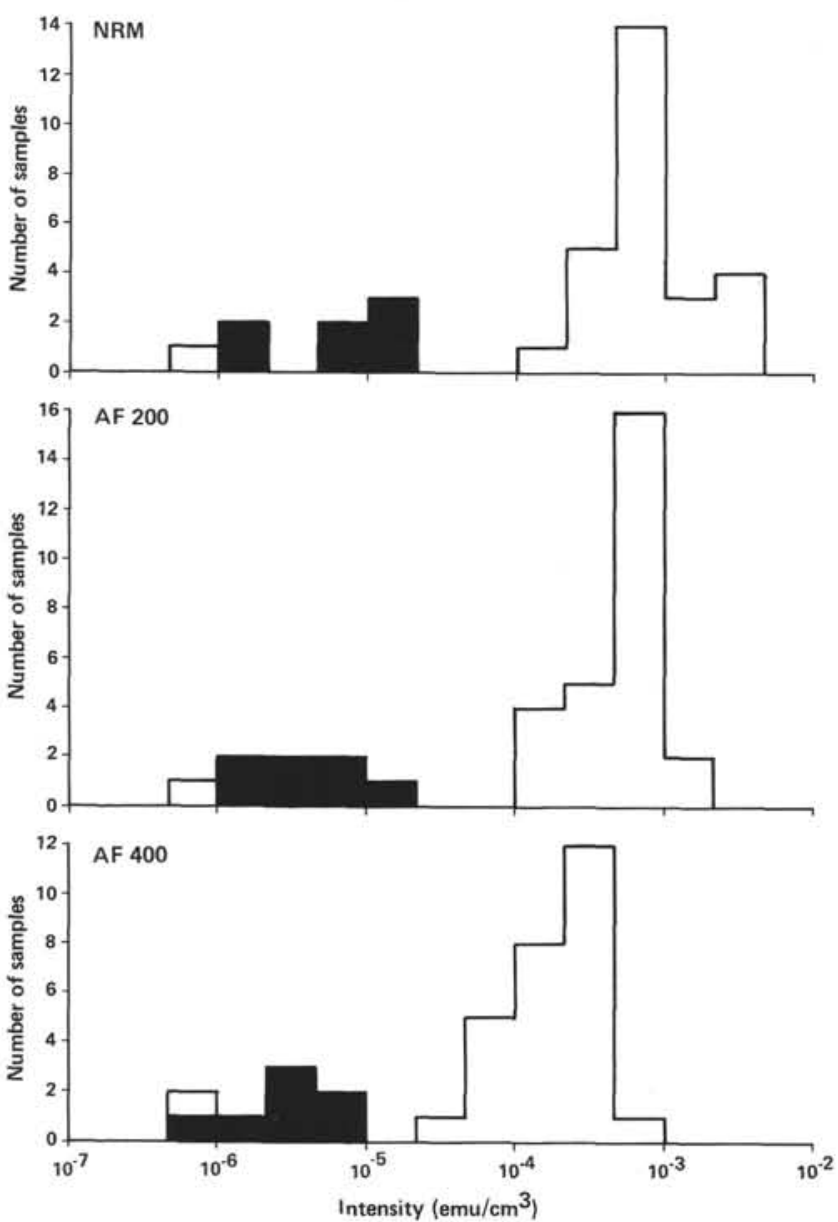

Figure 4. Distribution of NRM intensities and intensities after demagnetization to 200 and 400 Oe. Darkened pattern represents amphibolites. $\mathrm{AF}=$ alternating field demagnetization.

declinations between pairs of samples that were oriented relative to each other. In several cases, pairs of samples were taken from the same piece of core or uniquely fitting adjoining pieces in such a way that declinations as well as inclinations should agree. These samples are joined by brackets in Table 4 . One can observe that the values for Component 1 show considerably less consistency than those for Component 2, suggesting that Component 2 is indeed carrying the primary cooling remanence.

\section{Discussion}

The magnetic parameters for all samples are plotted in Figure 7. The five amphibolite samples are readily distinguished from the diabase by their low susceptibilities, as well as low NRM intensities. As can be noted in Figure 6, the amphibolites have a lower mean inclination $\left(10^{\circ}\right)$ than the diabases $\left(23^{\circ}\right)$. This suggests that their magnetization may date back to $500 \mathrm{Ma}$, the age of the amphibolites, or to the mild thermal event which occurred at $350 \mathrm{Ma}$ (Dallmeyer, this volume). However, their inclinations are not inconsistent with remagnetization during the Early Jurassic, so it is not possible to say with certainty when their magnetization was set. We prefer the interpretation that only the two stratigraphically highest amphibolite samples with negative inclina-

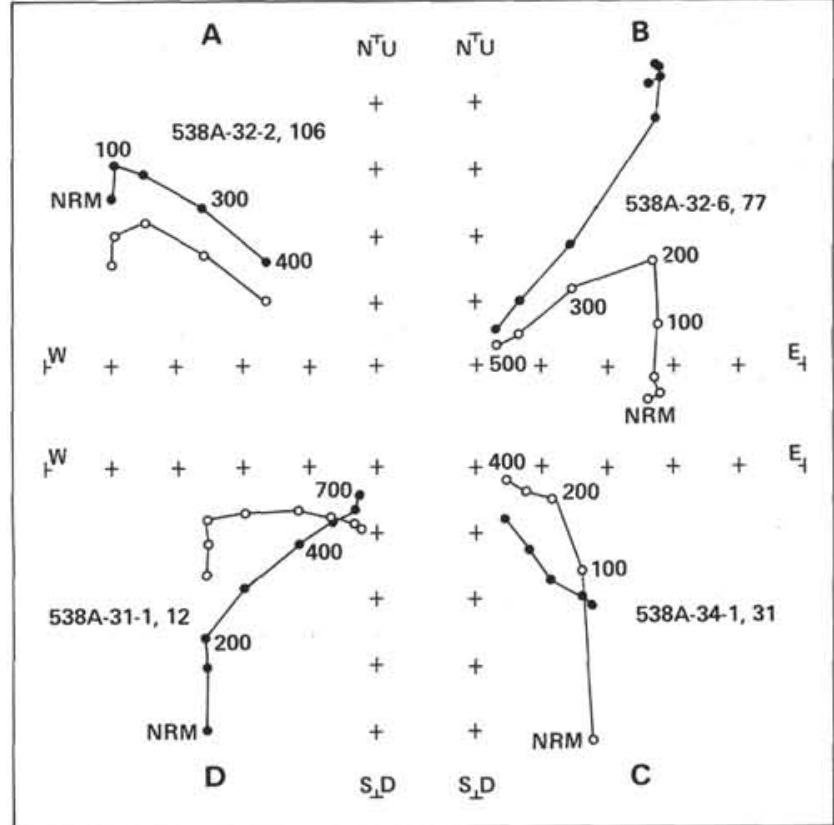

Figure 5. Exemplary orthogonal vector diagrams. Closed circles represent north versus east component: open circles indicate up versus East component. Numbers indicate peak alternating field in oersteds. A. Typical example described in text: a low coercivity component subtracted to $200 \mathrm{Oe}$ and then a stable component at higher demagnetization steps. B. Another diabase sample with a more detailed demagnetization history than A shows the same behavior. C. Amphibolite sample exhibits behavior very similar to diabase samples. D. One of the three cases in which a very high coercivity component remained after demagnetization to $700 \mathrm{Oe}$.

tions (538A-32-2, $81 \mathrm{~cm}$ and $538 \mathrm{~A}-32-2,90 \mathrm{~cm}$ ) were remagnetized during the intrusion of the overlying diabase (see Fig. 7 and Table 4). Reheating of the normally magnetized amphibolite by the reversely magnetized diabase intrusion would account for the intermediate inclinations observed at the top of the amphibolite. A TRM acquired in this manner would also explain the high mean demagnetizing field (MDF) of the two highest amphibolite samples.

The magnetic parameters put some constraints on the model of diabase intrusion. The diabase from Core 32 differs from the main diabase unit in Core 35 in its polarity, average inclination, $Q$, and NRM intensity. The $Q$ and intensity differences can be explained by a different cooling rate which would result in a different grain-size distribution. The opposite polarities are consistent with the interpretation of several generations of dikes. The topmost diabase sample from Core 35 may in fact represent a different intrusion than the samples from the main unit of Core 35. At least $1 \mathrm{~m}$ of amphibolite separates them, and the difference in stable inclination and susceptibility is significant (Fig. 7).

The polarities of the diabase in Core 36 present a confusing picture. Each sample was taken from a different piece and could therefore represent a separate diabase dike whose contacts were not recovered. Alternatively, one could call upon a reversely magnetized intrusion adjacent to the drill hole to remagnetize the three middle samples (see Fig. 7). 
Table 4. Parameters of magnetic remanence.

\begin{tabular}{|c|c|c|c|c|c|}
\hline \multirow{2}{*}{$\begin{array}{c}\text { Sample } \\
\text { (core-section, } \mathrm{cm} \\
\text { from top of section) }\end{array}$} & \multirow{2}{*}{$\begin{array}{c}\text { Mean } \\
\text { demagnetizing } \\
\text { (Oe) }\end{array}$} & \multicolumn{2}{|c|}{ Component 1} & \multicolumn{2}{|c|}{ Component 2} \\
\hline & & Decl. & Incl. & Decl. & Inc. \\
\hline $31-1,12$ & 325 & 178.8 & 30.9 & (228.1 & $-3.0)$ \\
\hline $31-1,23$ & 187 & 327.9 & 36.1 & 65.4 & -21.2 \\
\hline$\left\lfloor_{31-1,26}\right.$ & 361 & 305.2 & 62.4 & (77.2 & $-14.8)$ \\
\hline $32-1,21$ & 404 & 326.9 & 52.9 & 357.0 & -23.0 \\
\hline $32-1,85$ & $400+$ & 17.6 & 60.0 & 76.4 & -27.0 \\
\hline$L_{32-1,132}$ & 400 & 357.5 & 26.8 & 120.0 & -33.4 \\
\hline $32-2,30$ & 418 & 159.5 & 65.3 & 258.7 & -13.3 \\
\hline $32-2,106$ & 400 & 183.2 & 44.1 & 311.8 & -25.4 \\
\hline $32-3,70$ & $400+$ & 292.5 & 66.5 & 72.4 & -22.4 \\
\hline $32-3,90$ & 330 & 129.7 & 71.8 & 83.2 & -29.8 \\
\hline $32-4,16$ & 358 & 320.4 & 38.6 & $(44.3$ & 19.3) \\
\hline $32-5,33$ & 353 & 140.6 & 54.5 & 112.1 & -20.7 \\
\hline $32-5,68$ & 317 & 11.5 & 28.4 & 112.1 & -29.8 \\
\hline $32-5,141$ & 343 & 140.4 & 71.2 & 184.9 & -21.4 \\
\hline $32-6,77$ & 408 & 350.2 & 76.7 & 35.1 & -25.3 \\
\hline $32-7,25$ & 246 & 174.9 & 56.7 & 169.6 & -17.4 \\
\hline$a_{32-2,81}$ & $700+$ & 94.7 & 30.3 & 154.9 & -15.0 \\
\hline$a_{33-2,90}$ & $400+$ & - & - & 136.0 & -5.5 \\
\hline$a_{33-3,52}$ & 271 & 338.2 & 72.8 & 339.0 & 3.0 \\
\hline$a_{34-1,31}$ & 156 & 122.7 & 79.1 & 147.2 & 12.5 \\
\hline$a_{34-1,40}$ & 196 & 199.5 & 65.0 & 0.5 & 19.6 \\
\hline$a_{34-1,70}$ & 305 & 168.9 & 74.0 & 287.5 & 6.1 \\
\hline$a_{34-1,94}$ & 238 & 21.7 & 63.5 & 249.1 & 7.1 \\
\hline $35-1,14$ & 194 & 240.2 & 54.5 & 330.9 & 11.8 \\
\hline$[35-3,146$ & 177 & 347.3 & 76.6 & 83.3 & 37.2 \\
\hline$L_{35-4,18}$ & 314 & 243.5 & -36.1 & 84.1 & 37.2 \\
\hline $35-4,82$ & 161 & 7.5 & 54.0 & 27.3 & 30.3 \\
\hline $35-4,94$ & 254 & 204.1 & +15.8 & 353.5 & 38.1 \\
\hline$[36-1,57$ & 192 & 233.7 & 63.4 & 245.5 & 15.5 \\
\hline$L_{36-1,89}$ & 178 & 71.3 & 65.6 & 75.7 & -4.1 \\
\hline $36-2,86$ & 265 & 182.0 & 29.6 & 133.0 & -20.8 \\
\hline $36-2,92$ & 278 & 140.0 & 58.8 & 185.2 & -22.1 \\
\hline $36-3,21$ & 369 & 223.6 & 39.7 & 80.7 & 18.0 \\
\hline $36-3,27$ & 380 & 1.8 & 71.1 & (90.2 & 34.6) \\
\hline \multirow[t]{3}{*}{$36-3,46$} & 400 & 353.5 & 71.3 & 112.6 & 8.5 \\
\hline & & Mean & 54.8 & & 20.1 \\
\hline & & & $N=34$ & & $\mathrm{~N}=31$ \\
\hline
\end{tabular}

Note: Brackets mark the samples with a common orientation. Parentheses indicate the samples for which more than one high coercivity component was observed. These were not included in calculating the mean for Component 2 a Amphibolites.

The dike in Core 32 has been dated as $190.4 \pm 3.6 \mathrm{Ma}$ by Dallmeyer (this volume) who has also obtained a preliminary ${ }^{40} \mathrm{Ar} /{ }^{39} \mathrm{Ar}$ isotopic age of $160 \mathrm{Ma}$ for the main diabase unit in Core 35 (R. D. Dallmeyer, 1983, pers. commun.). The expected paleolatitudes and paleoinclinations at Hole 538A for this time period have been calculated using Harrison and Lindh's (1982) polar wander curve for North America and by assuming Hole $538 \mathrm{~A}$ was in its present position relative to North America.

\begin{tabular}{ccc}
\hline Ma & Latitude & $\begin{array}{c}\text { Inclination } \\
\left({ }^{\circ}\right)\end{array}$ \\
\hline 150 & $8.8^{\circ} \mathrm{N}$ & \pm 17.2 \\
160 & $7.3^{\circ} \mathrm{N}$ & \pm 14.4 \\
170 & $11.1^{\circ} \mathrm{N}$ & \pm 21.4 \\
180 & $3.8^{\circ} \mathrm{N}$ & \pm 7.6 \\
190 & $0.1^{\circ} \mathrm{N}$ & \pm 0.2 \\
200 & $2.5^{\circ} \mathrm{S}$ & \pm 5.0 \\
\hline
\end{tabular}

As the above table shows, Hole 538A has expected inclinations ranging from $\pm 0.2^{\circ}$ at $190 \mathrm{Ma}$ to $\pm 14.4^{\circ}$ at $160 \mathrm{Ma}$. The $11.6^{\circ}$ difference in average inclination
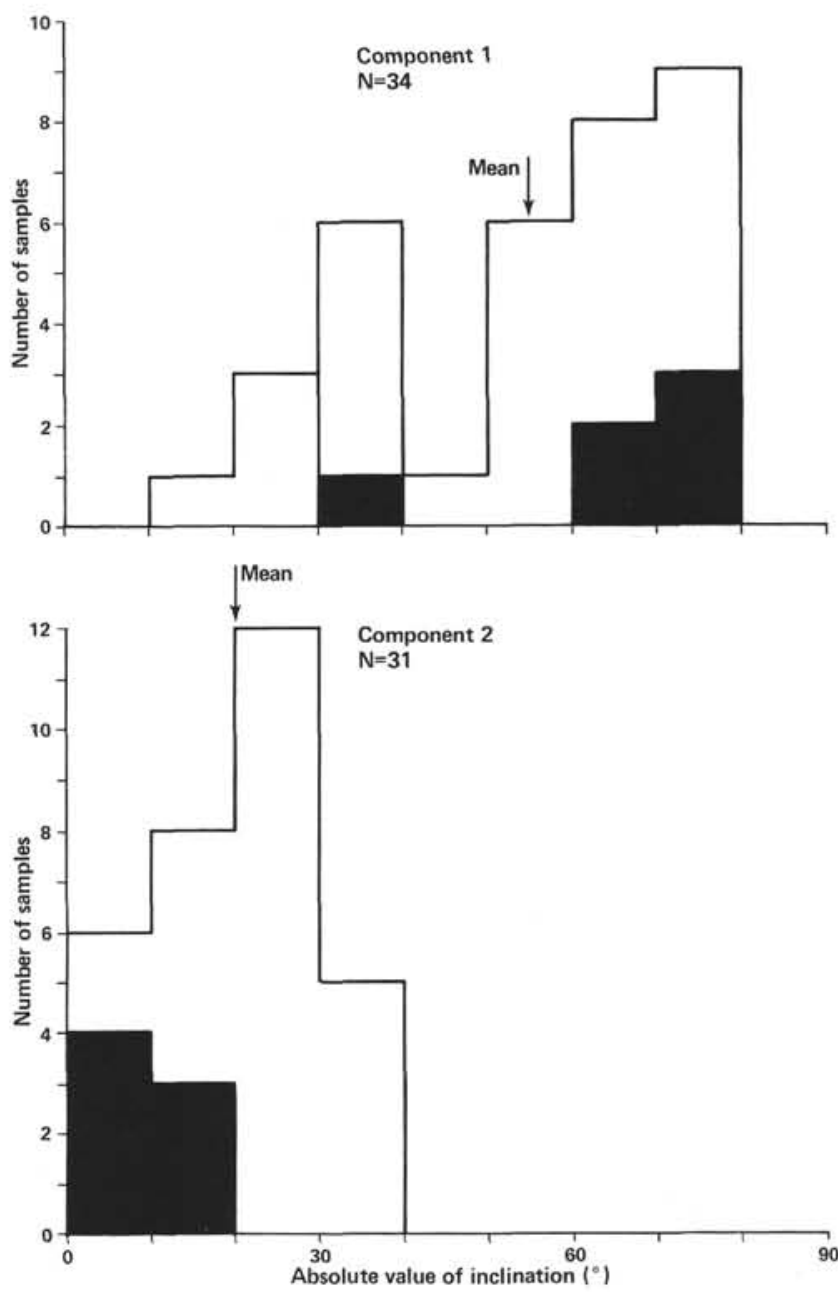

Figure 6. Distribution of absolute values of inclination for the two main components of magnetization. Darkened pattern represents amphibolites. $\mathrm{N}$ is number of samples.

between the dikes of Cores $32\left(35.7^{\circ}\right)$ and $35\left(24.1^{\circ}\right)$, although within the range of secular variation, corresponds remarkably well to the expected difference $\left(14.2^{\circ}\right)$ and thus supports the isotopic ages. However, the inclinations of both diabase units are steeper than expected, suggesting that the Catoche Knoll block tilted more than $20^{\circ}$ to the north after both dikes were intruded.

\section{SUMMARY}

As the low Königsberger ratios suggest, the basement rocks from Hole 538A can readily acquire a viscous remanent magnetization that can completely mask their original TRM. Therefore attempting to discern magnetic lineations in a seafloor composed of such rocks is difficult, if not impossible. A stable remanence was isolated by AF demagnetization to 200 Oe. The presence of normal and reverse polarities implies that the diabase intrusions spanned at least one magnetic reversal. The difference in magnetic inclination between two of the diabase units is consistent with their ${ }^{40} \mathrm{Ar} /{ }^{39} \mathrm{Ar}$ dates of 190 and $160 \mathrm{Ma}$. However, all inclinations are approximately $20^{\circ}$ steeper than expected, suggesting that the Catoche Knoll block tilted northward after the final dike intrusion. 

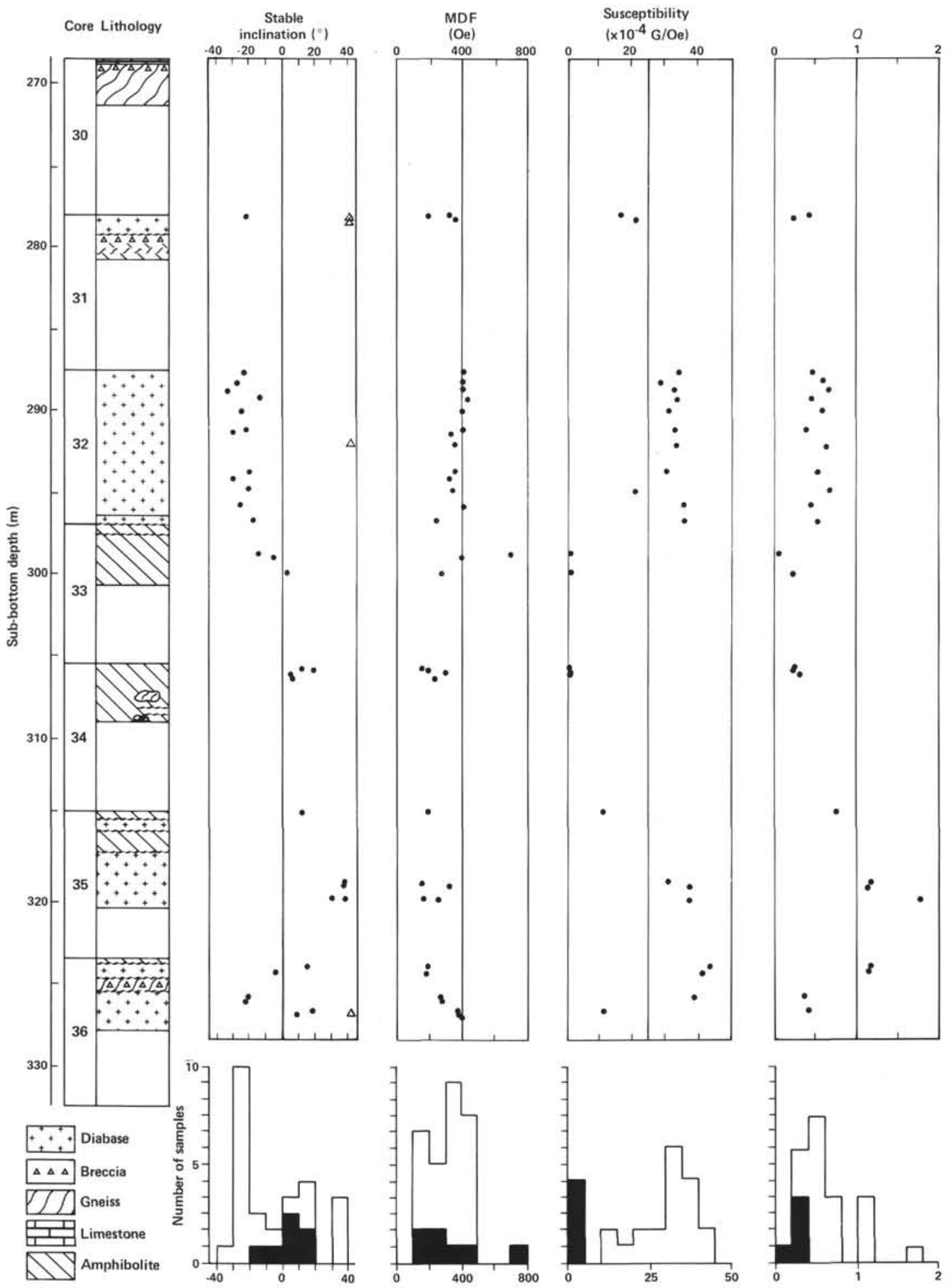

Figure 7. Magnetic parameters of basement rocks from Hole 538A. Triangles in the inclination graph indicate samples that did not have a stable inclination. Darkened pattern in the histogram represents amphibolites. $Q$ values are derived from land-based measurements of NRM intensity. Susceptibility and $Q$ values were not available for the nine samples added to the study postcruise. 


\section{ACKNOWLEDGMENTS}

We thank Dr. J. Ferraris, University of Texas at Dallas, and Dr. B. Ellwood, University of Georgia, for measuring the susceptibility of some samples for calibration purposes. Dr. R. D. Dallmeyer of the University of Georgia provided the isotopic ages before their publication. The reviews of Dr. R. Coe, University of California, Santa Cruz, and Dr. J. Hillhouse, U.S. Geological Survey at Menlo Park, were of considerable assistance in revising the manuscript. This work, supported by the University of Texas, is University of Texas Institute for Geophsyics Contribution No. 566.

\section{REFERENCES}

Chikazumi, S., 1964. Physics of Magnetism: New York (John Wiley \& Sons, Inc.).

Dunlop, D. J., 1983. Viscous magnetization of 0.04-100 $\mu$ m magnetites. Geophys. J. R. Astron. Soc., 74:667-687.
Gose, W. A., and Carnes, J. G., 1973. The time dependent magnetization of fine-grained iron in lunar breccias. Earth Planet. Sci. Letters, 20:100-106.

Harrison, C. G. A., and Lindh, T., 1982, A polar wandering curve for North America during Mesozoic and Cenozoic, J. Geophys. Res., 87:1903-1920.

Testarmata, M. M., and Gose, W. A., 1983. The susceptibility and time-dependent magnetization of basalts from DSDP Hole 534A, Blake Plateau. In Sheridan, R. E., Gradsein, F. M., et al., Init. Rept. DSDP, 76: Washington (U.S. Govt. Printing Office), 699-703.

Date of Initial Receipt: January 17, 1983

Date of Acceptance: November 1, 1983 